\title{
Study of hydrogen risk in a PWR-W containment during a SBO scenario; Tau parameter definition and application on venting strategy analysis
}

\author{
Kevin Fernández-Cosials, Gonzalo Jimenez*, Rafael Bocanegra, César Queral \\ Universidad Politécnica de Madrid, c/José Gutiérrez Abascal, 2, 28006 Madrid, Spain
}

A B S T R A C T

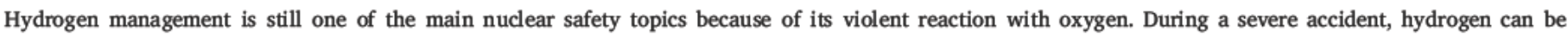

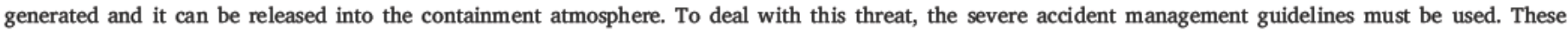

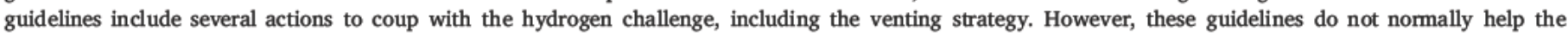
operators in deciding when the optimal moment to vent is.

In this study, a PWR-W GOTHIC 3D containment model is used to simulate a station blackout scenario. The venting and spraying strategy and their impact on

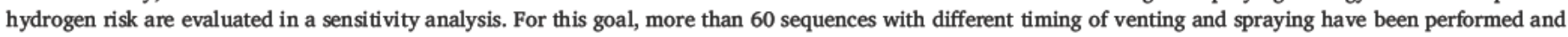
analyzed.

To compare all simulations between each other, a quantitative approach to hydrogen risk was needed. Therefore, hydrogen risk is estimated and quantified using a

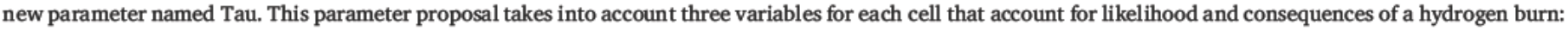

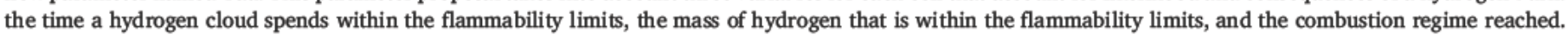
With this parameter, a single value can be obtained to quantify the hydrogen risk in a full transient.

Finally, reviewing the sensitivity analysis, it is observed that hydrogen risk is highly dependent on the venting strategy used, increasing it if performed prior to

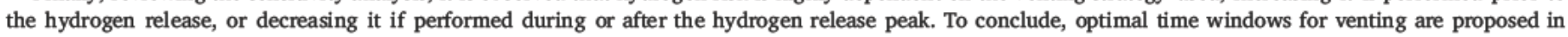
order to reduce the hydrogen risk during the transient.

\section{Introduction}

Severe Accidents (SAs) in Nuclear Power Plants (NPPs), and speci fically hydrogen management, have hardened over more than 30 years due to its considerable hazardousness, its difficult prediction, and its importance to society. During a SA in a Light Water Reactor (LWR), large quantities of hydrogen can be generated during the reactor core degradation. This hydrogen can be released into the containment at mosphere, and could react violently with oxygen. Therefore, hydrogen combustion during a SA becomes one of the most significant hazards to the containment integrity, (Kljenak et al., 2012).

In 1979, during the Three Mile Island (TMI) accident, approxi mately 350 kilograms of hydrogen combusted in the containment creating a pressure spike of 2.8 bars (Kljenak et al., 2012). Since the TMI 2 containment withstood this load, there were no consequences for the people and the environment. Thirty two years later, on 2011, the earthquake and latter tsunami that stroke the Fukushima Dai ichi NPP caused a Station BlackOut (SBO) in which large amounts of hydrogen were generated. Three hydrogen explosions occurred, damaging the containment integrity and drawing again the international attention to the hydrogen issue, (OECD/NEA, 2013).

Hydrogen combustion can impair the containment integrity, but depending on how it burns, it can be more or less hazardous. The in teraction between hydrogen and oxygen during a combustion is a combination of more than 20 chemical reactions identified as the San Diego mechanism, (Sánchez and Williams, 2014). The resultant com bustion regime is influenced by several variables such as pressure, temperature, mixture concentration, turbulence or confinement geo metry, (Camp et al., 1983). The combustion regimes, from the point of view of nuclear safety, are classified into three regimes; Slow Defla gration (SD), Flame Acceleration (FA), and the Deflagration to Deto nation Transition (DDT) (OECD/NEA, 2000). These regimes have been extensively studied in several facilities and institutions to assess the hydrogen risk in containment, such as FZK (Fortschungzentrum Karls ruhe, Germany), KI (Kurchatov Institute Moscow, Russia), NUPEC (Nuclear Power Engineering Corporation, Japan), CEA (Commissariat a

\footnotetext{
* Corresponding author.

E-mail address: gonzalo.jimenez@upm.es (G. Jimenez).
} 
l'Energie Atomique, France) or NRC (Nuclear Regulatory Commission, USA) (Karwat et al., 1999).

The first step to estimate the hydrogen risk in computational si mulations, is to identify what type of combustion regime will appear in the transient. Given that these regimes prediction are mostly based on species concentration, the correct gases transport and distribution is critical to assess the hydrogen risk (Xiao and Travis, 2013). To simulate hydrogen distribution in a NPP containment, the use of CFD or con tainment codes with 3D capabilities is broadly accepted as it can ac curately reproduce this phenomena, (OECD/NEA, 2014a,b). Con sidering the large volume of a typical PWR containment (50000 $65000 \mathrm{~m}^{3}$ ), the problems simulating steam condensation, and the presence of at least three species make the assessment of hydrogen risk with a CFD code a challenging task. Nonetheless, there are suc cessful hydrogen CFD studies in the past, see (Bauwens and Dorofeev, 2014; Kudriakov et al., 2008; Martín Valdepeñas et al., 2007; Philipov and Filipov, 2014; Prabhudharwadkar et al., 2011) as well as contain ment 3D codes studies, see (Bielert et al., 2001; Grgić et al., 2012; HSE, 2011; Jong Tae et al., 2004; Kim and Hong, 2015; Papini et al., 2015; Royl et al., 2000; Serrano et al., 2016). Specifically, OECD/NEA has stated that the use of 3D containment codes for safety analyses has been established as a useful tool for hydrogen distribution within the con tainment and capable to determine local and global hydrogen con centration with a reasonable precision (OECD/NEA, 2010).

During a SA, the Technical Support Center (TSC) personnel use the Severe Accident Management Guidelines (SAMGs) to support the de cision making process, being these guidelines plant specific (NEI, 1994). Even though NPPs were not initially designed to withstand a SA, these guidelines attempt to mitigate the radiological consequences of the accident. Therefore, SAMGs final objective is not to protect the reactor core but to limit fission product releases to the environment (EPRI, 2012). It must be noticed that these are guidelines and not procedures; therefore, during a SA, the TSC must take decisions on how to prioritize hazards and what to do to mitigate them (Vayssier et al., 2012).

If hydrogen is generated during a SA and certain limits are sur passed (normally about $4 \%$ of hydrogen concentration in dry air), the decision diagram leads to the guideline that helps the TSC to mitigate the risk: the Severe Accident Guideline 7 (SAG 7) "Reduce containment hydrogen". If the flammability conditions inside the containment could lead to its failure then the Severe Challenge Guideline 3 (SCG 3) "Control Hydrogen Flammability" is activated. As stated before, a hy drogen combustion can produce the containment impairing and limit its safety function, so the correct implementation of SAG 7 and SCG 3 are important during a SA, (EPRI, 1992).

There are several ways to manage hydrogen risk during a SA. It is possible to reduce hydrogen concentration and/or mass inside the containment to limit the deflagration consequences. It is also possible to reduce the oxygen mass in the containment, which will limit the hy drogen combustion.

A current strategy is focused in the Passive Autocatalytic Recombiners (PARs). These devices convert hydrogen and oxygen into water, by a catalytic reaction. The recombination rate can be moderate, but it helps in reducing the amount of hydrogen in the containment. The working conditions of this recombiners have a specific range; they cannot operate above certain limit of hydrogen concentration (varies between $5 \%$ and $8 \%$, depending on the model), as they can act as ig niters, and they need, as well, a minimum of $12 \%$ of hydrogen to start operating, (Bachellerie et al., 2003; Reinecke et al., 2010).

When performing actions during a SA, it is possible that some ac tions interfere with other challenges, creating a worst condition or vice versa (IAEA, 2009). As an example, spraying the containment will help in reducing the containment pressure, lowering the containment da mage risk and reducing the Fission Products (FP) present in the atmo sphere. However, this action will condensate steam, and consequently rise the oxygen and hydrogen gas volume fractions, and therefore, it will increase the hydrogen and containment damage risk. All this phenomena have to be taken in consideration when the TSC is per forming SAMG actions, such as containment venting, operating the hydrogen igniters or spraying the containment (EPRI, 2012).

In detail, the containment venting strategy has both pros and cons regarding the hydrogen risk depending on the time of venting. An early venting strategy can reduce the mass of hydrogen and/or oxygen, which will make the possible hydrogen burn less energetic, but it can increase hydrogen concentration later in the accident, affecting the combustion regime and inducing a DDT instead of a SD combustion. This is why it is particularly interesting to investigate the timing for this strategy (OECD/NEA, 2014c).

In this paper, an SBO simulation in a PWR W containment is per formed using the GOTHIC code. A sensitivity analysis on the venting strategy is also included to estimate the optimal timing for containment venting that minimize the hydrogen risk.

In the first section of the paper, a brief description of the GOTHIC 8.1 code is presented. In the second section, the GOTHIC PWR W containment model is depicted. Then, a description of the computa tional criteria to evaluate the hydrogen risk, the Tau parameter, is ex plained. The following sections cover the SBO simulation and its ana lysis focusing on the hydrogen risk. Afterwards, the sensitivity analysis results is exposed and explained, and finally, some proposals for the SAG 7 are made as a conclusion.

\section{Models and methods}

In this section, the code and the containment model used to perform the analysis is shown. In addition, the conception and development of the Tau parameter is explained with the normalization made for this specific work.

\subsection{The GOTHIC code}

GOTHIC (Generator of Thermal Hydraulic Information in Containments) is an integrated, general purpose thermal hydraulics software package for design, licensing, safety and operating analysis of nuclear power plant containments, confinement buildings and system components (EPRI, 2014).

GOTHIC can solve the conservation equations for mass, momentum and energy for multi component, multi phase flow for three fields: gas mixture, continuous liquid and droplets. A finite volume method is used, and cell volume and surface porosities are used to model complex geometries. It also includes full treatment of the momentum transport terms in multi dimensional models, with optional models for turbulent shear and turbulent mass and energy diffusion. In contrast to standard CFD codes, GOTHIC does not have a body fitted mesh capability. GOTHIC uses empirical 1D correlations for the heat transfer between the fluid and the structures rather than attempting to model the con vection specifically. The subdivision of a volume into a multi dimen sional grid is done in orthogonal coordinates exclusively (EPRI, 2014).

The 3D capabilities of GOTHIC in simulating basic flows, and in detail, hydrogen flows for containment analysis have been investigated extensively, simulating test in facilities like PANDA, CSTF, BFMC or CVTR (EPRI, 2014). A large validation effort against light gas experi ments has been made with 2D and 3D models, see (Andreani et al., 2012, 2010, 2008, 2003; Fernández Cosials et al., 2016; Hultgren et al., 2014; Paladino et al., 2010). The version of the code used in the present research is GOTHIC 8.1 (QA), (EPRI, 2014).

\subsection{PWR $W$ containment model}

The containment building of a typical large dry PWR W has been modeled with the GOTHIC code. A summarized model description is explained below. This model has been created based on a CAD model, see Fig. 1. Detailed information about the original model can be found 


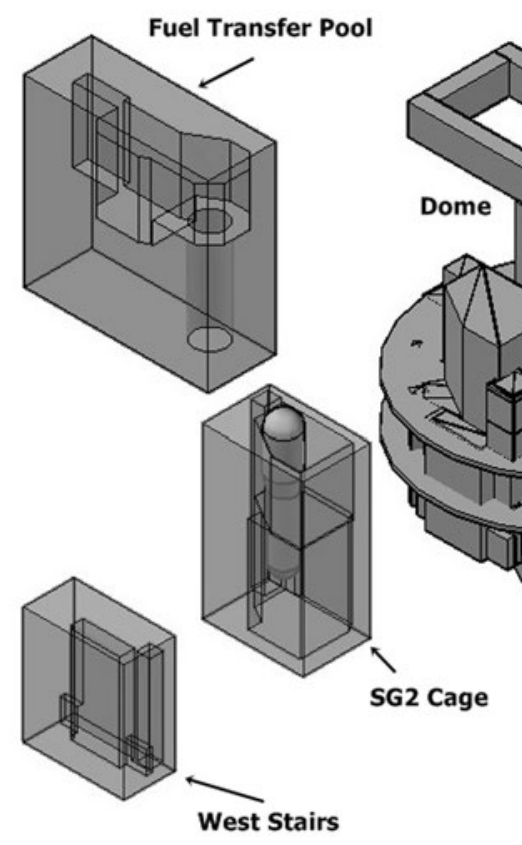

Fig. 1. Containment volumes in at very high temperatures,

( CAD model (Bocanegra et al., 2016).

in (Bocanegra et al., 2016).

The GOTHIC containment model consists of 11 Control Volumes (CV) connected by flow paths and/or 3D connectors, see Fig. 2. Each CV

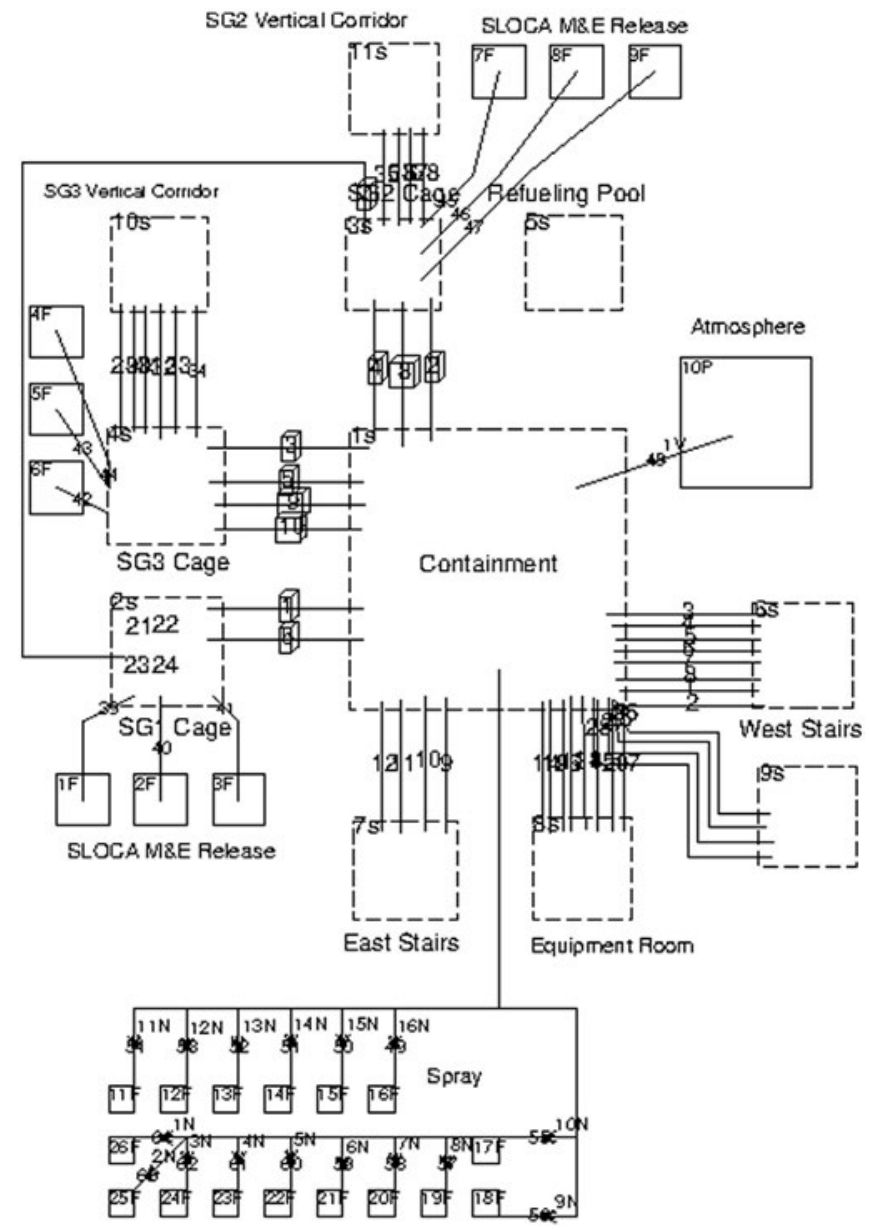

Fig. 2. GOTHIC containment model.
Table 1

Control volume representation for the PWR-W GOTHIC containment model.

\begin{tabular}{lll}
\hline $\begin{array}{l}\text { Control Volume } \\
\text { Identification }\end{array}$ & Represented Region & Number of Cells \\
\hline CV 1 & Main Volume & 1377 \\
CV 2 & SG 1 Cage \& PZR cage & 84 \\
CV 3 & SG 2 Cage & 63 \\
CV 4 & SG 3 Cage & 63 \\
CV 5 & Fuel Transfer Pool & 126 \\
CV 6 & West Stairs & 18 \\
CV 7 & East Stairs \& SG1 vertical & 30 \\
& corridor & \\
CV 8 & Equipment Rooms & 30 \\
CV 9 & Lower Equipment Rooms & 8 \\
CV 10 & SG 3 Vertical Corridor & 14 \\
CV 11 & SG 2 Vertical Corridor & 16 \\
\hline
\end{tabular}

represents a region within the containment, see Table 1 . CV 1 re presents the upper part, the dome and open regions inside the con tainment.

The mesh has to be fine enough to account local phenomena. The refinement will also determine the computational cost of the model, so the mesh should not be too fine so the model becomes inoperable. Accordingly, to achieve an adequate accuracy cost ratio, the GOTHIC model used in the analysis has 1829 cells, with an average cell di mensions of $5 \times 5 \times 5 \mathrm{~m}$. As seen in the study of Bocanegra et al. (2017) this mesh is fine enough to capture the relevant phenomena for gas transport with an adequate accuracy.

The calculational parameters of the PWR W GOTHIC model are shown in Table 2. The pressure matrix solution method used was con jugate with the flux variables calculated up stream with a space dif ferencing scheme of second order (BSOUP).

The spray system is modeled using 16 Boundary Conditions (BCs) to represent the three spray rings in the containment dome. The total flow of a typical PWR W spray system at full capacity is divided among the BCs with an injection of $15 \mathrm{~kg} / \mathrm{s}$ per spray component (Huang et al., 2011) and a droplet diameter of $0.05 \mathrm{~cm}$. The venting system is mod eled as a $\mathrm{BC}$ at $101 \mathrm{kPa}$ connected through a flowpath located at $41 \mathrm{~m}$ height based on a PWR W venting line location, (Burelbach et al., 2015). 
Table 2

PWR containment GOTHIC model parameters.

\begin{tabular}{|c|c|c|c|c|c|c|}
\hline Turbulence model & Molecular diffusion & Minimum porosity & Pressure control & Enthalpy control & Max. Time step & Discretization scheme \\
\hline $\mathrm{k}-\varepsilon$ standard & Enabled & 0.01 & $6.89 \mathrm{kPa}$ & $2.326 \mathrm{~J} / \mathrm{g}$ & $0.01 \mathrm{~s}$ & BSOUP \\
\hline
\end{tabular}

Thermal Conductors (TCs) are used to model the heat capacity of solid structures, heat transfer between the fluid and these structures, heat transfer through solid structures separating CVs, and heat sources associated with the structures. To represent the thermal connection in the 3D models, several TCs were used connecting thermally different regions separated by a wall, and also to model the condensation over the different surfaces, including the Steam Generators (SGs), the liner and the polar crane. Therefore, 228 spanned TCs were implemented in the model.

For convective heat transfer, the fluid temperature and the Heat Transfer Coefficient (HTC) are calculated using different correlations. Specifically, for natural convection, the McAdams correlations (McAdams, 1954) are set for the different surface types, (EPRI, 2014).

The DLM FM condensation model is used for the walls in contact with the containment atmosphere. A heat flux with a nominal value fixed to zero is used in the internal side of the heat sinks such as the polar crane. The internal face of the Reactor Cooling System (RCS) pipes and pumps surface temperatures were fixed to the primary system temperature. The external atmosphere temperature was fixed to $35^{\circ} \mathrm{C}$ and a HTC of $11.35 \mathrm{~W} / \mathrm{m}^{2}{ }^{\circ} \mathrm{C}$ was set for the exterior convective heat transfer as seen in (Ofstun and Scobel, 2006).

\subsection{Evaluation of the hydrogen risk; the Tau parameter}

In this section the qualitative and quantitative approach to the hy drogen risk is exposed together with some hydrogen combustion properties. The Tau parameter is obtained as the result of a quantitative approach to hydrogen risk, seen as the product of likelihood and con sequences of a hydrogen burn.

\subsubsection{Hydrogen combustion regimes}

In nuclear safety, the combustion regimes are classified into three regimes according to CSNI R(2000)7 (OECD/NEA, 2000):

- Slow Deflagration (SD): the flame velocity is lower than the speed of sound of the reactant. The velocities can reach $200 \mathrm{~m} / \mathrm{s}$ and the pressure increase is in the order of the initial pressure. To assess this regime, the flammability criterion can be used.

- Flame Acceleration (FA): the flame velocity is higher than the re actants sound velocity but slower than the products one (approxi mately $500 \mathrm{~m} / \mathrm{s}$ ). The pressure increase is about ten times the initial pressure. To assess this regime, the sigma criterion can be used.

- Deflagration to Detonation Transition (DDT): the flame velocity is higher than the reactants and the products sound velocity. In this case the velocity of the flame can reach $1200 \mathrm{~m} / \mathrm{s}$ and the pressure increases about 30 times the initial pressure. To assess this regime, the lambda criterion can be used.

There are different criteria to identify in which combustion regime the hydrogen cloud is. Those are the flammability criterion, which de termines SD and it is adapted to the data and studies of (Byun et al., 2000; Stamps and Berman, 1991). The Sigma Criterion determines the possibility of FA, and it is based on the works of FZK and KI, (Breitung and Royl, 2000; Dorofeev et al., 2001). Finally, the Lambda Criterion which predicts a DDT situation and it is based on the studies of KI, (Dorofeev, 1996). This criterion is implemented computationally in this work as it has been implemented in several successful studies such as (Gómez Torres et al., 2015; Xiao et al., 2017). These three combustion regime criteria take into account variables that can be extracted from a calculation cell, such as the species concentration, characteristic length of the container, pressure, temperature and properties of each species.

In this study, the computational implementation of these criteria will follow the steps of the work from (Martín Valdepeñas et al., 2007) with the update made in the last corrigendum (Martín Valdepeñas et al., 2007). Following these criteria, every cell of the model is eval uated under the mentioned limits via a post processing code developed in a Matlab environment (Mathworks, 2015). However, it is worth mentioning that there are more variables involved in hydrogen com bustion like the turbulence of the mixture and the Damköhler numbers (Williams, 1985). These last variables have not been taken into account in this study.

\subsubsection{Hydrogen ignition}

Hydrogen can auto ignite itself at very high temperatures, (Boivin et al., 2011). Its dependence on the auto ignition time is proportional to several parameters, such as pressure, concentration or temperature. However, the auto ignition time of hydrogen mixtures at low tem peratures (below $500 \mathrm{~K}$ ) is extended. Under these circumstances, it is more likely that the hydrogen needs an external source for its ignition than an auto ignition.

The external source of ignition can be as small as a simple spark, or a hot surface. In a NPP there are hundreds of potential sources for ig nitions that can initiate the combustion (Knudson et al., 2015). Therefore, in nuclear safety, it is important to maintain the containment atmosphere the fewer time possible in flammability conditions to avoid a random ignition. Studies on hydrogen risk normally do not take into account the ignition sources, because of the random feature of this process during an accidental sequence; they usually focus on the gas concentration and mixture properties to calculate the hydrogen risk, even though there are successful studies that consider the mixture ig nition (Bielert et al., 2001).

\subsubsection{The Tau parameter, $(\tau)$}

In this section a new parameter $(\tau)$ is proposed to evaluate the hy drogen risk in computational models with high complexity. Risk is normally defined as the product between likelihood and consequence of an event, so the Tau parameter will take this into account in its nu merical form. In addition, when performing several simulations, it is important to reduce to a common indicator all simulations results so this large amount of information is gatherable in a single parameter. Actual research uses indicators such as possibility of DDT, FA or SD, but those simulations are not easily comparable between each other in terms of hydrogen risk. Consequently, a new parameter is needed to make hydrogen risk quantifiable and suitable for models with a large number of computational cells.

As stated before, the consequences of a hydrogen burn depend on its combustion regime. This means that a burning within SD regime will have small impact compared to a detonation within the DDT regime. Therefore, the Tau parameter have to be a function of the combustion regime.

In addition, it should also be proportional to the time spent within a combustion regime. A lower likelihood of deflagration is achieved when 
a hydrogen mixture is within the flammability limits during a period of minutes than a period of hours. For this reason Tau has to be function of the time spent within the limits.

Finally, the mass of hydrogen in this regime has also been taken into account. The reason is that the consequences of combusting $1 \mathrm{~kg}$ of hydrogen instead of $100 \mathrm{~kg}$ are totally different in terms of damage.

Concluding, taking into account these considerations, the Tau parameter is defined as a function of the combustion regime, the time inside such regime and the mass of hydrogen within the limits:

$\tau=f($ Comb Regime, Time, Mass)

With the previous remarks, the Tau parameter dependence is qua litatively defined. In the following sections will be defined quantita tively. The definition will be made in order to indicate that a higher Tau will imply a higher hydrogen risk.

2.3.3.1. Combustion regime hazard. In this section, a quantitative approach to the hazard of each combustion regime will be depicted. There are several examples among the literature where the hydrogen different combustion regimes are presented, as previously discussed in Section 2.3.1. In addition, an estimation of the damage that a hydrogen deflagration can provoke can be found in the works of (Dorofeev, 2007). In this study, a blast criterion is exposed in terms of pressure increase and distance to the ignition. An adaptation of this criteria is made to categorize the hazardousness of each regime. Under this criteria, the PWR W containment is supposed to be a low congestion region. Thus, taking into account the pressure peaks and the velocities that each regime produces, a multiplier is applied depending on them:

- Slow Deflagration (SD): This regime will have a multiplier of 0.4. This is because the pressure load produced by this regime is below the containment design limits. However, the temperature increase produced could impair the function of internal components, in strumentation systems and/or equipment, which are qualified for a maximum atmosphere temperature close to 148.9 C (IEEE, 1974). This equipment and/or instrumentation damage could produce malfunctions in components that are vital to manage the accident progression, and that would lead to a worse final state of the plant.

- Flame Acceleration (FA): a multiplier of 0.85 is used. Its impact on the containment can be noticeable, provoking its possible impair ment. It is dependent on the mass of hydrogen burned. The pressure load can damage internal walls or systems. In addition, this regime will reach the equipment and instrumentation limits for temperature (IEEE, 1974).

- Deflagration to Detonation Transition (DDT): a multiplier of 1 is applied, given that the conditions during this scenario cannot be easily withstand by any equipment, system or instrumentation. The pressure spike provoked has the potential to impair the contain ment. It could even be argued that if a combustion under a DDT regime occurs near the primary system, it could produce a LOCA on the RCS.

Once the Tau parameter dependence on the combustion regimes is quantitatively defined, it can be expressed as:

$\tau=0.4 \cdot f_{S D}($ Time, Mass $)+0.85 \cdot f_{F A}($ Time, Mass $)+f_{D D T}($ Time, Mass $)$

Being $f$, functions of time and mass of every combustion regime.

2.3.3.2. Time hazard. The time spent in certain regime must be another important term on the equation. The longer the time a mixture is under SD, FA or DDT conditions the higher the likelihood of a random spark, and therefore an ignition process. As an example, it has been suspected that the spontaneous burn produced during the TMI accident was initiated by a ringing telephone (OECD/NEA, 2000); therefore the time the cell spends in certain regime is considered for the quantitative approach of hydrogen risk. Thus, taking into account the combustion regime and the time spent within the limits the Tau parameter is defined as:

$\tau=0.4 \cdot t_{S D} \cdot f_{S D}($ Mass $)+0.85 \cdot t_{F A} \cdot f_{F A}($ Mass $)+t_{D D T} \cdot f_{D D T}($ Mass $)$

Being $t_{\mathrm{SD}}, \mathrm{t}_{\mathrm{FA}}$ and $\mathrm{t}_{\mathrm{DDT}}$, the time the cell has spent in SD, FA or DDT regime respectively.

2.3.3.3. Mass hazard. In order to take into account the mass dependence, the time value will be multiplied by the mass which is currently under those flammability conditions. Then, the hydrogen risk takes into account not only that the mixture is flammable and the time that is on those conditions, but also the mass that stays on those conditions. Finally, the Tau parameter is completely defined as:

$\tau=0.4 \cdot t_{S D} \cdot m_{H 2}+0.85 \cdot t_{F A} \cdot m_{H 2}+1 \cdot t_{D D T} \cdot m_{H 2}$

Then applied to a computational model, every time step, the com bustion limits are evaluated on each cell of the model, then, if those limits are overpassed, the hydrogen mass inside the cell at that time is calculated. This mass is multiplied by the time step size and by the combustion regime correspondent multiplier, and afterwards, this process is repeated for the next time step. To obtain a single value for a simulation, the Tau values obtained for each cell of the model will be added up, creating the total Tau of the simulation. With the total Tau a quantification of the hydrogen risk of a transient has been achieved.

$\tau_{\text {tot }}=\sum_{i=1}^{N \text { cells }} \tau_{i}$

It is relevant to mention that the linearity of the mass and time factors is a necessity. This is because Tau is designed to be mesh in dependent and time step independent. Otherwise, a change in the mesh or the time step while simulating the same transient in the same con tainment, would provide a different Tau value simply because of nu merical reasons.

2.3.3.4. Tau normalization. In order to provide information just by the Tau figure, a normalization is needed. It will be chosen to the following limit: If the total Tau of the simulation reaches or surpasses the value of "1", the consequences are assumed dangerous and unavoidable. Accordingly, in this paper, TMI accident will be chosen as the normalization values given that it is the only source of data of a random ignition process inside a real PWR containment. Ideally, the normalization should be made taking into account the characteristics of the plant that is being analyzed, but because of the lack of data, TMI conditions are used to provide certain usefulness of the Tau figure obtained.

There are some uncertainties on TMI accident data, but it is some what accepted that core uncovery started $130 \mathrm{~min}$ after the accident initiation and that the random ignition of hydrogen was produced about $8 \mathrm{~h}$ later. At the beginning, hydrogen flowed off the RCS through the Pressurizer (PZR) relief tank. From the first hydrogen generation to its ignition, approximately $27000 \mathrm{~s}$ passed. That means that the hy drogen was floating around $27000 \mathrm{~s}$ on the containment without com bustion. It is therefore assumed that if a determined quantity of hy drogen is inside the containment for more than $27000 \mathrm{~s}$, the combustion would occur with high probability. In order to normalize the Tau parameter, the time during which the mixture is under combustion characteristics is divided by 27,000 .

During the TMI accident, approximately 350 kilograms of hydrogen combusted (Kljenak et al., 2012). Therefore, following the previous criterion, the hydrogen mass is divided by 350 kilograms.

To combine both factors, the total mass of hydrogen generated and the time it was in the containment are multiplied, obtaining 9450000 kilograms seconds. To increase the danger of the value " 1 ", the nor malization is made assuming the mixture under DDT regime.

Resuming, a hydrogen mixture that satisfies the lambda criterion 
(DDT regime) for $27000 \mathrm{~s}$ with a mass of 350 kilograms will reach Tau equal to " 1 ". This means that damage inside the cell and its sur roundings is almost unavoidable, damaging the containment and its internals. It should be noticed that this parameter can be greater than 1 , indicating that damage is very probable as it surpasses TMI conditions extensively. Concluding, the normalized Tau parameter for this study is:

$\tau=0.4 \cdot \frac{t_{S D}}{27000} \cdot \frac{m_{H 2}}{350}+0.85 \frac{t_{F A}}{27000} \cdot \frac{m_{H 2}}{350}+1 \cdot \frac{t_{D D T}}{27000} \cdot \frac{m_{H 2}}{350}$

\section{SBO reference sequence}

In this section, the SBO sequence is presented together with its implementation in the GOTHIC model. Then, the simulation results are analyzed in order to obtain the Tau parameter (hydrogen risk).

\section{1. $M \& E$ release input}

The reference sequence is a SBO scenario with Alternate Current (AC) recovery at $10000 \mathrm{~s}$ in a 3 Loop PWR $\mathrm{W}$ that avoids the vessel failure but not the core damage. This sequence has been extracted from the literature (Martín Valdepeñas et al., 2000), and it has been applied in recent studies (López Alonso, 2016). It maximizes the hydrogen generation during the in vessel phase but it avoids the ex vessel phase. The first leakage occurs through the pump seals creating a Seal LOCA (SLOCA) at $500 \mathrm{~s}$. The first hydrogen release starts approximately after 7000 s. Following NUREG/CR 6158 (Kuan et al., 1994), the most un favorable situation for hydrogen generation is when the core reflood occurs when its temperature is very high (about $1800 \mathrm{~K}$ ). The core reaches this state at $9000 \mathrm{~s}$, just before the accumulators injection. The injected water is rapidly evaporated, starting an intense steam zirco nium reaction with the consequent hydrogen generation. After $10000 \mathrm{~s}$, $\mathrm{AC}$ is assumed recovered, and therefore the safety injection systems, so the hydrogen generation is assumed to stop. The $\mathrm{M} \& \mathrm{E}$ release for this sequence is shown in Figs. 35.

\subsection{Reference SBO sequence GOTHIC simulation}

The $\mathrm{M} \& \mathrm{E}$ release input is implemented in the GOTHIC containment model in order to obtain the Tau of the simulation. The SLOCA is modeled using $9 \mathrm{BCs}$ (one for each loop, phase and species), and located near the pumps of the correspondent loop. The transient lasts $20000 \mathrm{~s}$ in order to decrease computational cost. The simulation took $21 \mathrm{~h}$ to complete the calculation, using 8 cores of $2.2 \mathrm{GHz}$ each. For post processing the output, the variables are averaged in volume and por osity for each CV of the model, using an upgraded version of ProTON, (Bocanegra et al., 2016). This version of ProTON calculates the aver aged values for pressure, temperature or species concentration for each $\mathrm{CV}$, as well as the Tau parameter (hydrogen risk). The simulation results are shown in Figs. 6 and 7.

As shown in Fig. 6, hydrogen concentration is not homogeneous inside the containment during part of the transient. At the beginning of the sequence, the hydrogen concentration starts to rise in all regions, being quicker in the breaks surroundings. The highest peaks occur after the core reflood due to the accumulators injection. This rapid release of hydrogen creates the highest concentration peak (13.2\%) located in CV 10. At that moment, the hydrogen distribution has differences in con centration ranging between $1035 \%$ between the different CVs. CV 5 is assumed isolated provoking that its properties remain almost constant. The differences in hydrogen concentration at the beginning of the transient are similar to the ones found in the literature, (Commission of the European Communities, 1991; Papini et al., 2015). Approximately $3600 \mathrm{~s}$ after the end of the $\mathrm{M} \& \mathrm{E}$ release, the hydrogen concentration is stabilized and homogenized in the whole containment, with small dif ferences due to height. The final hydrogen concentration is approxi mately $9 \%$. No stratification was observed at the end of the simulation time $(20000 \mathrm{~s})$.

The most dangerous combustion regime achieved is shown in Fig. 7. In this graph, when a CV reaches " 1 ", it represents that the SD regime is reached in at least one of its cells, " 2 " for FA and " 3 " for DDT com bustion regime. Concerning the worst combustion regime achieved, it can be seen that the SD regime is quickly achieved in all regions as soon as the hydrogen concentration starts to rise inside them. The FA is achieved afterwards in all CVs, with an initial peak in CV 2 due to a hydrogen cloud movement. The hydrogen concentration continues to rise, and lambda criterion is satisfied in certain CVs leading to DDT conditions during hundreds of seconds, moving down to the FA com bustion limits until the end of the simulation.

The pressure and temperature evolution of the sequence can be observed in Figs. 8 and 9. The hydrogen and steam/water release in creases the pressure and temperature in all CVs. The pressure inside the containment does not reach the set point established for the venting for pressure relief or the set point for entering SAG 6 "Control Containment Conditions" ( $\approx 140 \mathrm{kPa}$ ). In addition, the temperature stays below the equipment and instrumentation limit $\left(148.8^{\circ} \mathrm{C}\right)$ in all containment re gions, so local damage is supposed to be avoided, see (Jimenez et al., 2017).

Adding up all Tau values of each cell of the model, and normalizing

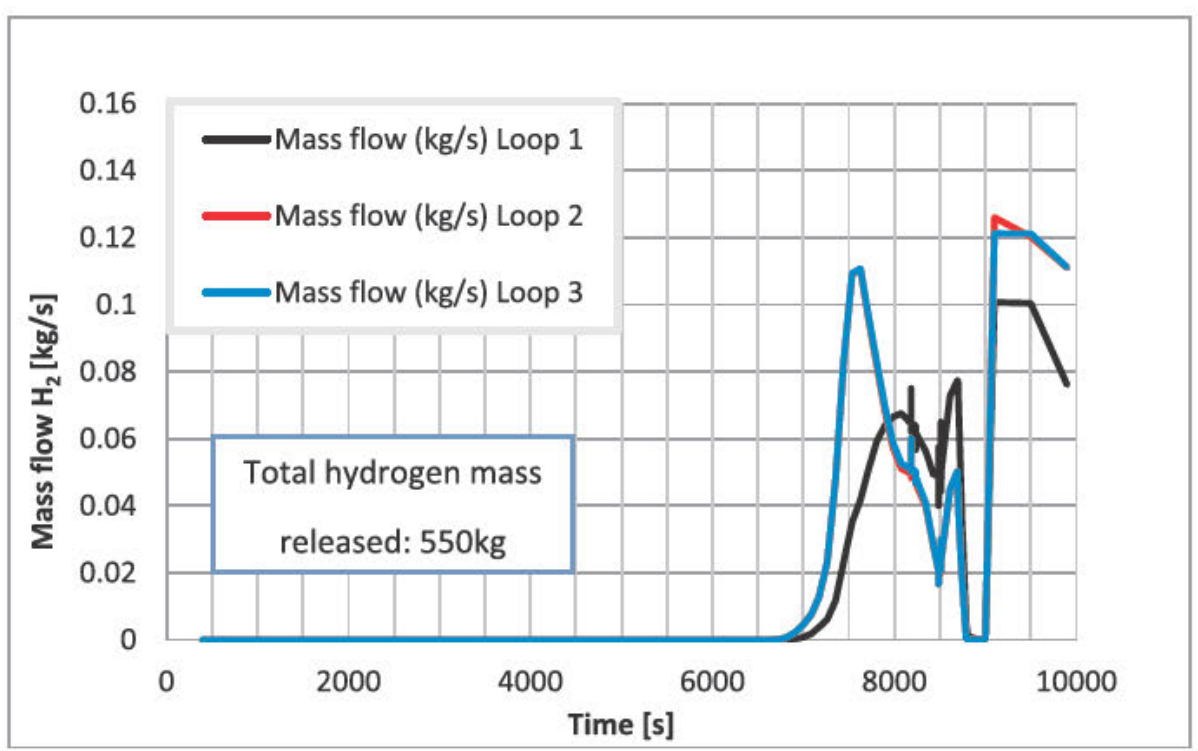

Fig. 3. Hydrogen source from the pump seals (SBO reference case). 


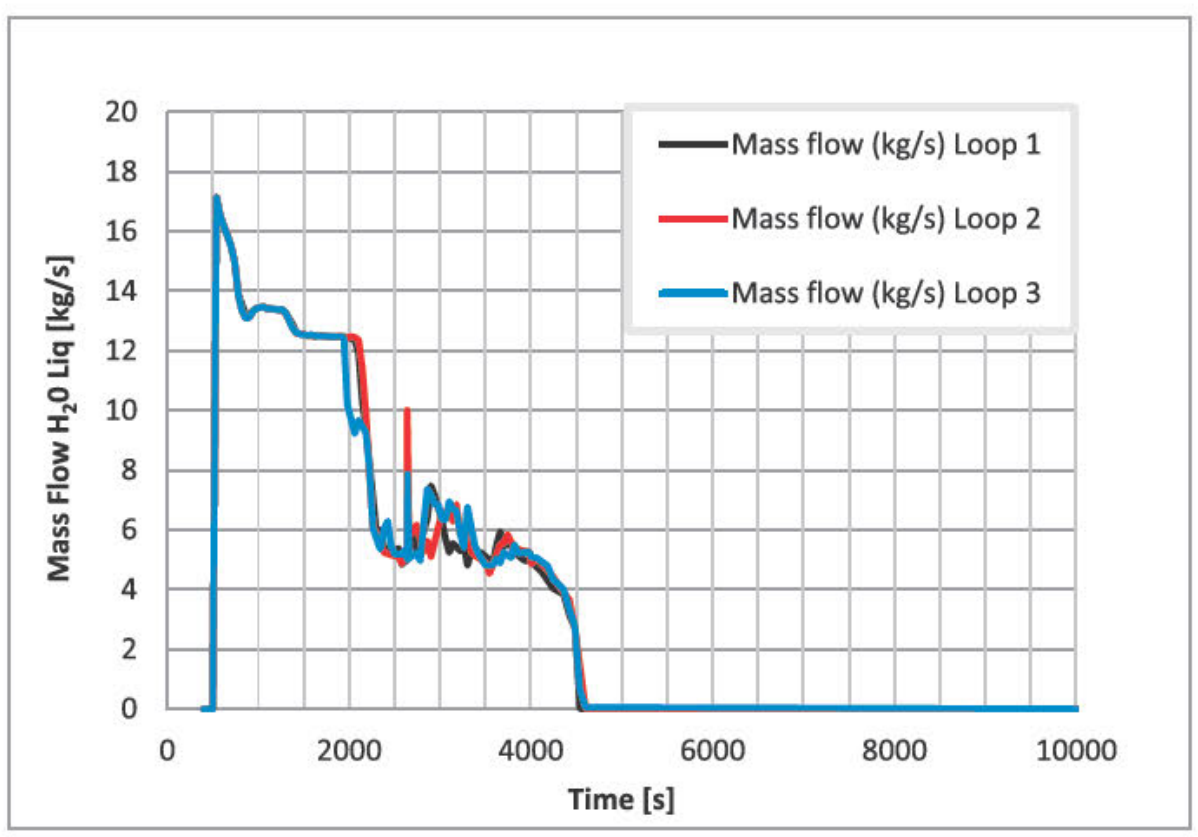

Fig. 4. Liquid water source from the pump seals (SBO reference case).

to TMI like conditions, provides a total Tau of $\mathbf{0 . 5 5 3}$. This indicates that the hydrogen risk is high and that a random ignition is somewhat probable. The Tau temporal evolution for each $\mathrm{CV}$ can be seen in Fig. 10. The mayor contributor to the total Tau is CV 1 (the containment dome and open regions), because it occupies the largest volume and holds the mayor part of the hydrogen mass. Tau increases rapidly during the first and second hydrogen release, and afterwards, it aug ments more slowly because the DDT regime is no longer possible and the hydrogen mass remains constant inside the containment.

\section{Sensitivity analysis for human actions}

Once the Tau parameter is established as a quantitative indicator of the hydrogen risk, an analysis on human actions, concerning the spray and the venting strategies, is made. In this sense, a sensitivity study, which includes 65 simulations, has been performed to cover a wide range of venting and spray timing. To achieve an adequate computa tional cost, the simulations were finished after $20000 \mathrm{~s}$ of transient. Each simulation took approximately $22 \mathrm{~h}$ using 8 cores of $2.2 \mathrm{GHz}$ each.

It is assumed that before venting the containment, it should be sprayed to reduce the atmosphere FP concentration as it is normally encouraged by SAMGs (EPRI, 2012). If there is no other option, the venting process will be executed without spraying in order to protect the containment integrity and equipment against hydrogen deflagra tions or detonations. The opening of the isolation valve for initiating the venting is normally a human action that does not require AC or DC, and can be performed during a SBO. The venting strategy does not have neither a starting point nor a fixed duration, so combinations of short, long, early and delayed venting are considered. The spray is set to function during $2000 \mathrm{~s}$, based on particle retention studies (del Corno et al., 2017) and it starts before the venting in all cases. It is assumed that the spray could start at any time during the transient even if the AC is not yet recovered thanks to the support of FLEX equipment (NEI, 2012).

The large number of simulations analyzed is necessary because venting or spraying the containment have both positive and negative impacts on hydrogen risk that are difficult to predict. On the one hand, the sprays induce a mixing on the containment that could decrease high concentration zones of hydrogen (Malet and Huang, 2015). On the other hand, spraying the containment could enhance steam

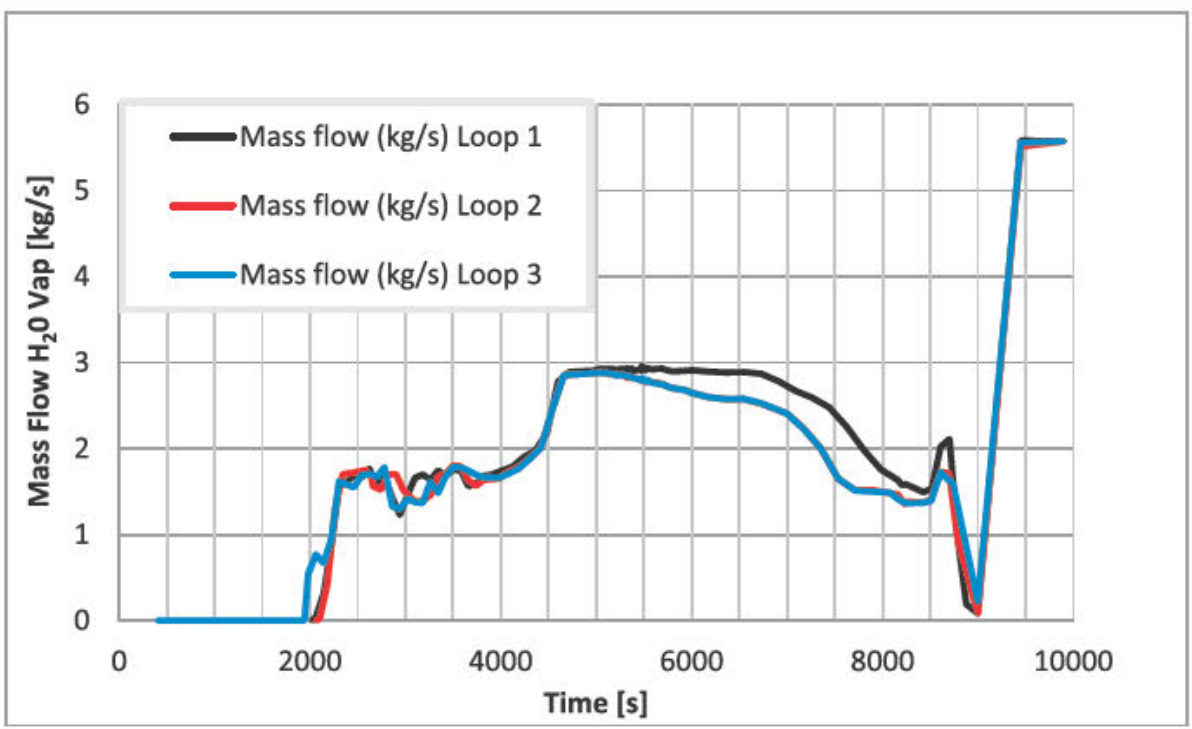

Fig. 5. Vapor source from the pump seals (SBO reference case). 


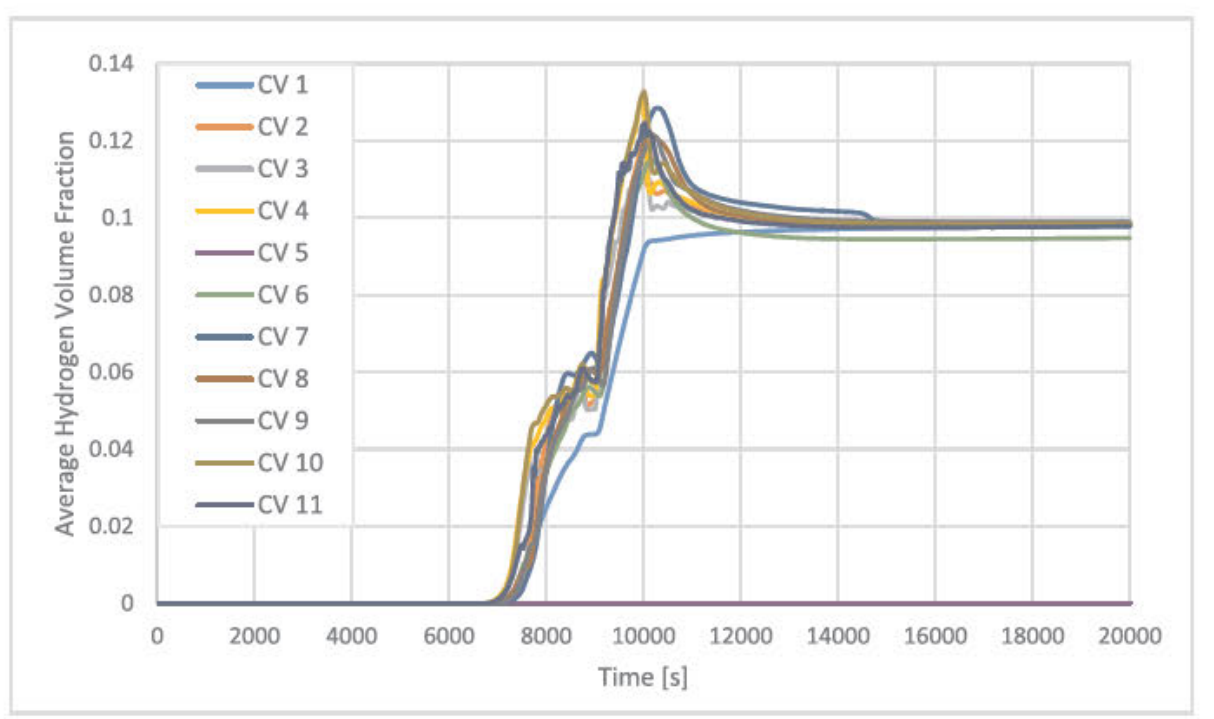

Fig. 6. Average hydrogen concentrations inside the containment CVs (SBO reference case).

condensation, and this phenomenon would increase the oxygen and hydrogen volume fraction leading to severe combustion regimes, ( $\mathrm{Li}$ and Cao, 2015). The venting strategy positive and negative effects have been previously explained in the introduction section, and they are difficult to predict altogether, (OECD/NEA, 2014c).

The key parameter compared in the sensitivity analysis is Tau. To extract a tendency, Tau is compared against the venting start, the venting length and the delay between the spray and the venting as can be seen in Fig. 11. In this figure, the Tau parameter is plotted against the venting starting time, the area of the bubble is proportional to the duration of the venting procedure and the color of the bubble is de pendent on the time between spray and venting.

Analyzing Fig. 11, it is seen that the early venting strategy, that intends to decrease the oxygen concentration before the hydrogen is released, is definitely not an adequate strategy as it cannot evacuate that much oxygen and, in addition, it lowers the steam concentration which makes the atmosphere less inert. As a consequence, it will in crease the hydrogen volume fraction and strengthen the combustion regime. Resuming, the early venting strategy increases the hydrogen risk. There is no clear tendency at these initial moments on when to vent to increase the tau value as minimum, as shown in Fig. 11. Fur thermore, there is no clear tendency as well on the duration of the venting on these early moments before the hydrogen release at $7000 \mathrm{~s}$.
In addition, the venting operation produces flow patterns inside the containment that influence the hydrogen risk which cannot be easily predicted, see Fig. 12. Moreover, cases with or without spray on this early moments have no clear differences on hydrogen risk.

However, right after the beginning of the hydrogen release, a ten dency can be observed regarding the hydrogen risk. The closer the venting starting time is to the secondary hydrogen peak production (9000 10000 s) the lower the Tau value drops. This is because if the venting occurs during this phase, the hydrogen peak, which leads to the DDT regime, is avoided on most of the CVs. This makes the Tau value to drop, and in addition, as the venting operation is executed once the hydrogen release has started, several hydrogen kilograms will be vented, reducing even more the total hydrogen risk. The total mass of hydrogen evacuated by a $1000 \mathrm{~s}$ venting after the hydrogen peak is approximately 100 kilograms, which represent about an $18 \%$ of the total hydrogen released. This strategies lead to approximately $20 \%$ reduction of the Tau value relative to the no venting scenario.

Once the hydrogen is released, it can be stated that the longer the venting the better, because more hydrogen will be evacuated from the containment, reducing the Tau value.

Additionally, Fig. 11 shows that there is no clear tendency on the optimal moment for the spray operation to reduce the hydrogen risk; the spray have a small effect compared to the venting starting time.

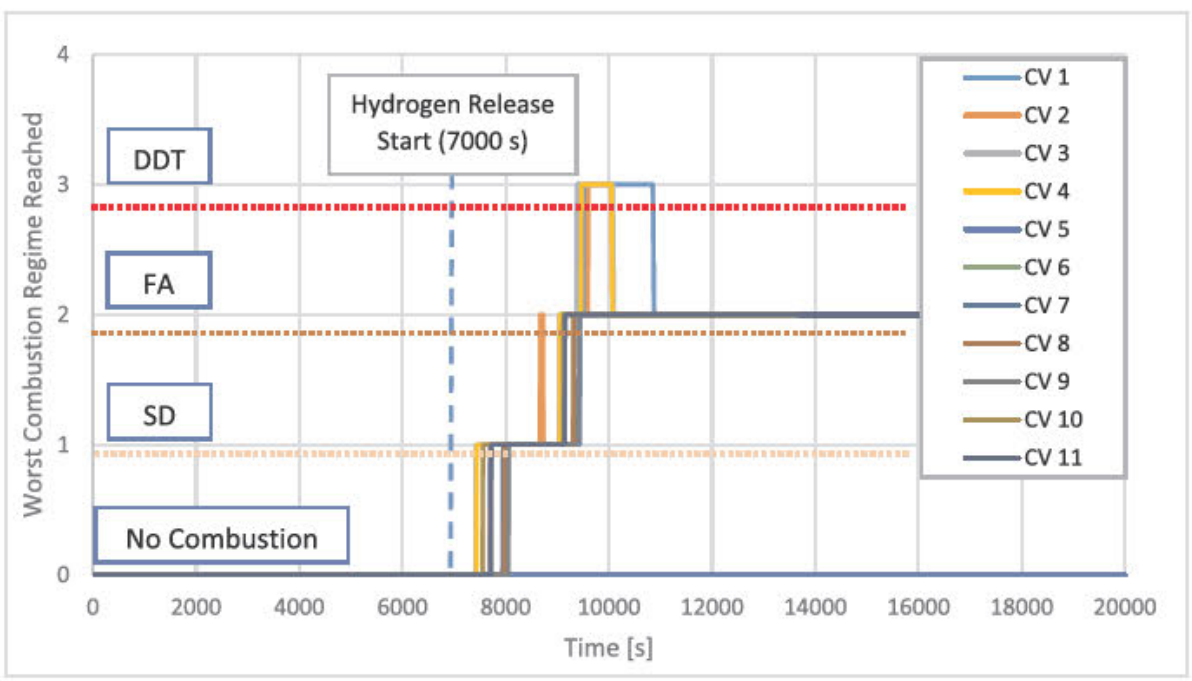

Fig. 7. Combustion regime reached inside the containment CVs (SBO reference case). 


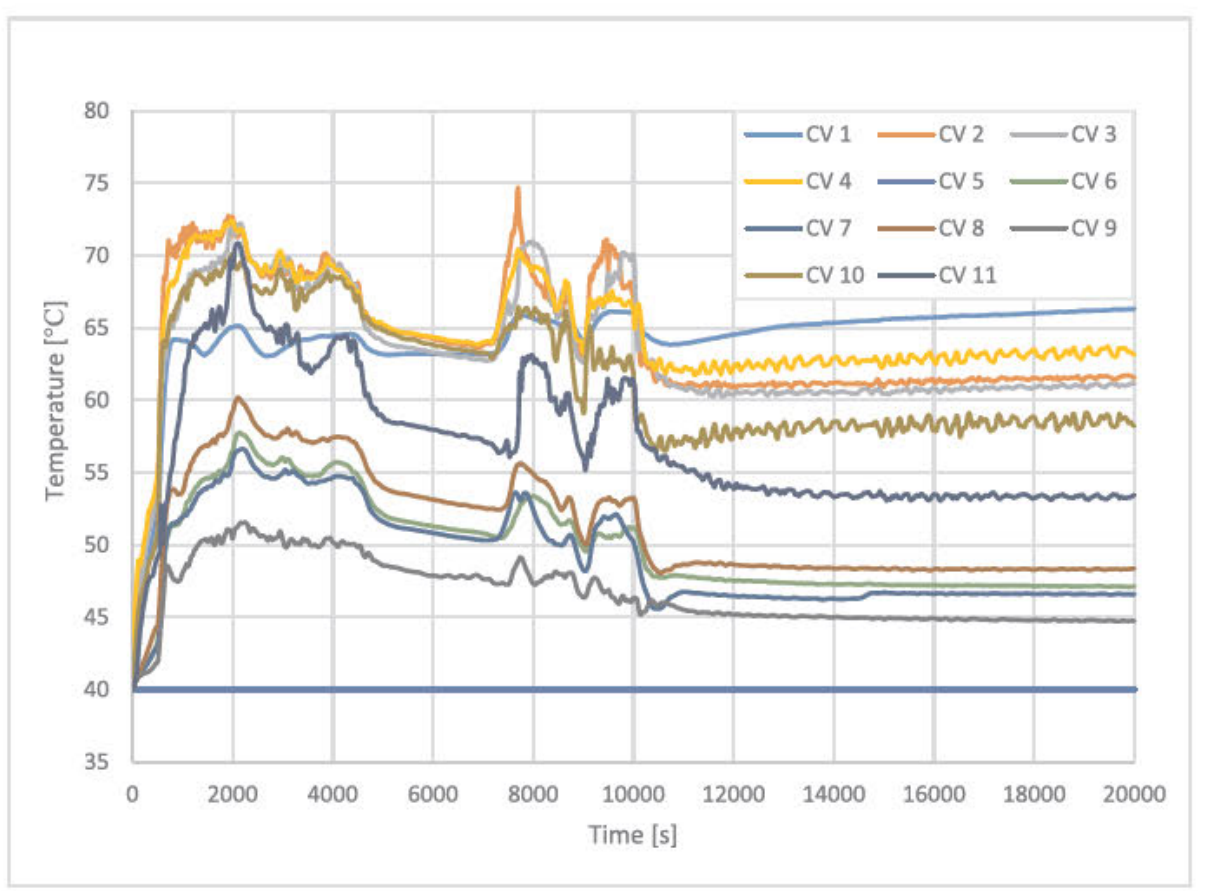

Fig. 8. Average temperatures inside the containment CVs (SBO reference case).

There is small influence if the spray is activated at the time coincident with the hydrogen peak, because the spray will condense steam, and consequently that will increase the hydrogen volume fraction at the moment when the DDT regime can be achieved. It must be commented that in other type of transients with a higher content of steam, such as a LBLOCA or SBLOCA, this influence could be much higher.

Fig. 13 shows the Tau temporal evolution for five specific cases. It can be seen that the cases where the vent is performed earlier, its slope is reduced before, and consequently, the final Tau is lower. In addition, the spray does not significantly modifies the Tau trend, and the main influencer are the venting operation and the hydrogen release. More over, the simulation that reduces the amount of gases inside the con tainment prior to the hydrogen release, have a higher slope because of the higher hydrogen volume fraction resultant. The tau change rate over time is shown in Fig. 14. It is remarked that the mayor contributors are the venting starting time and the hydrogen releases.

\section{Results discussion and proposal}

As it has been discussed on the previous section, some venting strategies can considerably reduce the hydrogen risk. The simulations show that the Tau value can be reduced not only by reducing the hy drogen mass inside the containment, but also by limiting the worst deflagration possible. For this reason, an early venting action could be based on hydrogen concentration.

Fig. 15 shows the gas volume fractions in the containment upper region. This concentration could be captured by a hydrogen monitor in this location. This indicator should be powered by batteries in order to

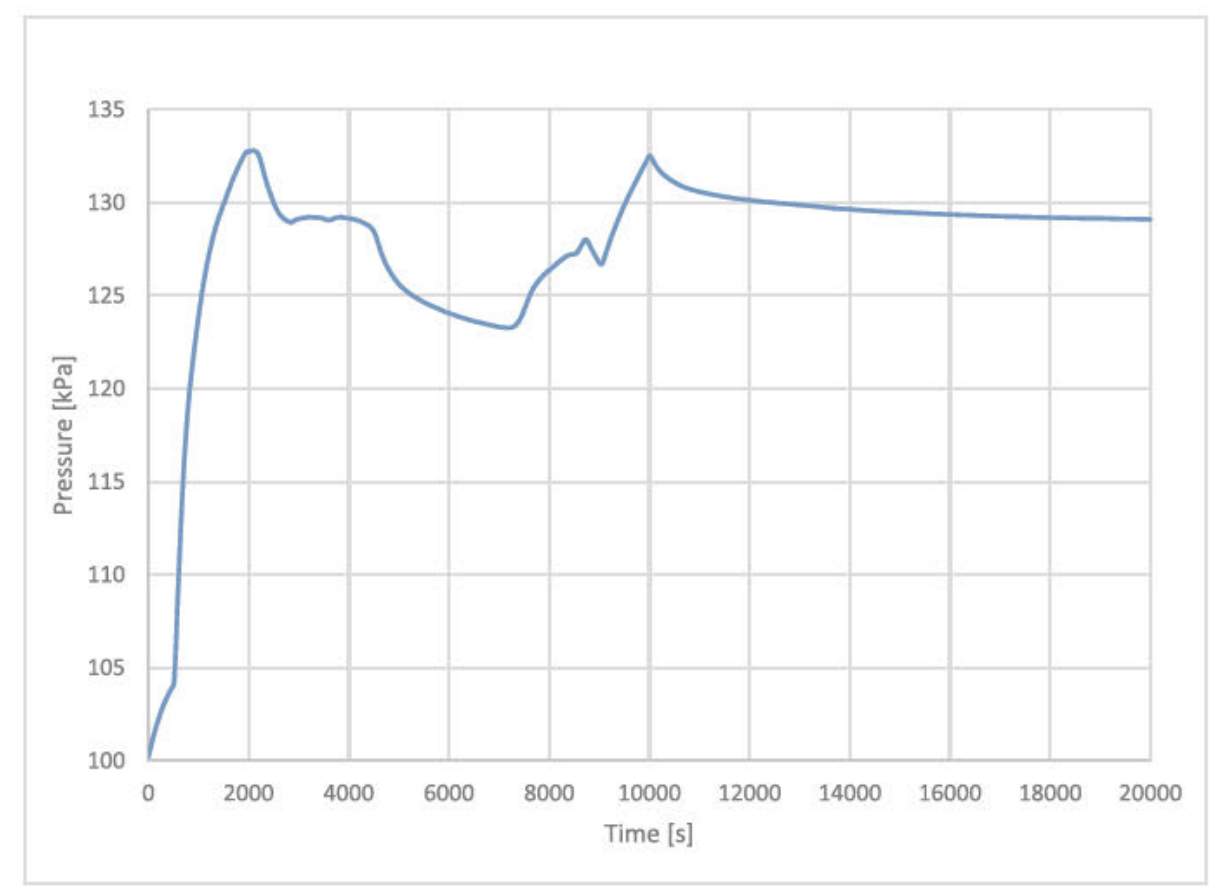

Fig. 9. Average pressure inside the containment (SBO reference case). 

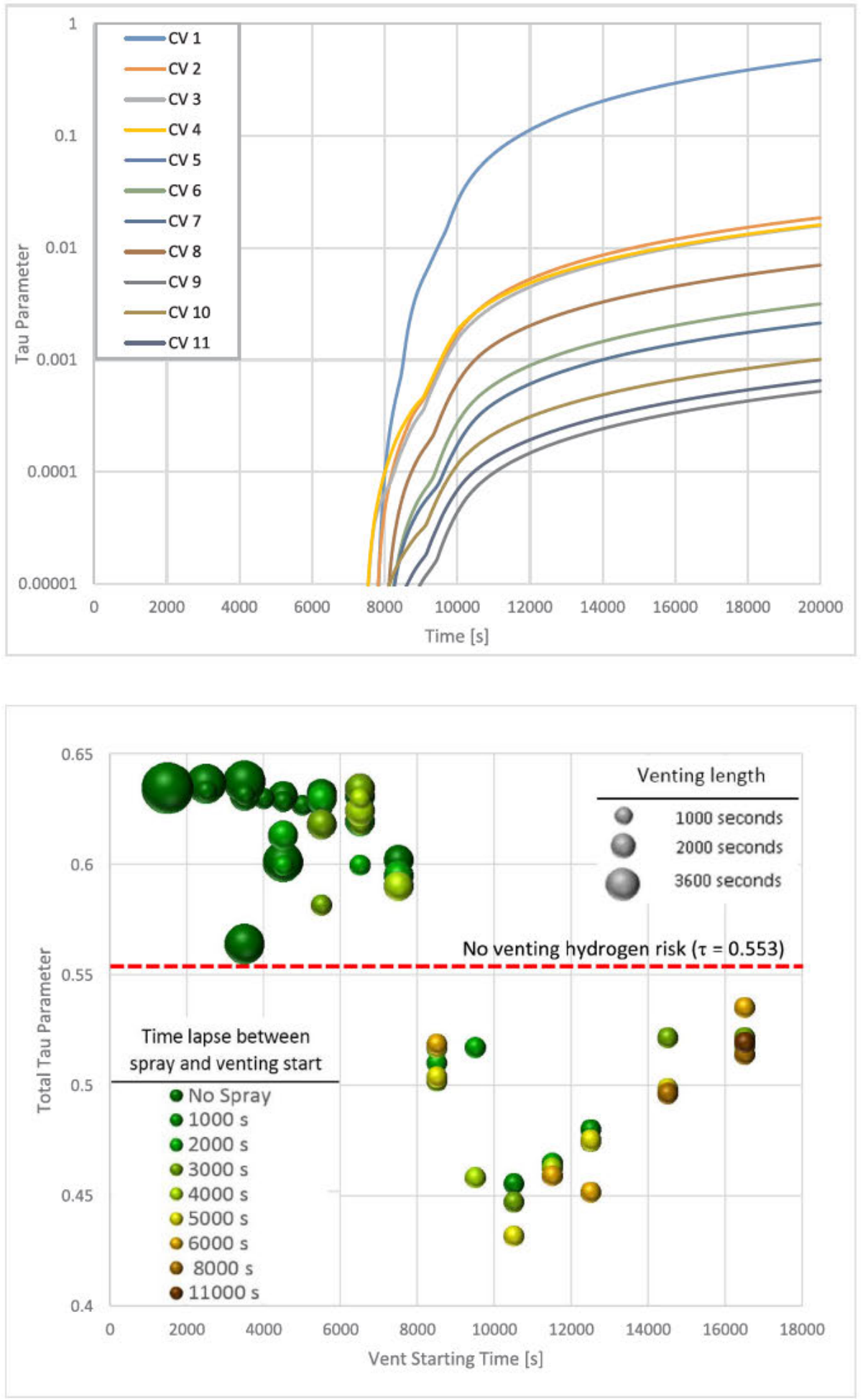

Fig. 10. Tau evolution in the containment CVs (SBO reference case).

Fig. 11. Tau value of sensitivity analysis on human actions. be available during a SBO transient. According to this graph, the op timal period for venting would be between 8500 and $12500 \mathrm{~s}$ after the beginning of the transient. Note that this venting operation time is for this specific SBO scenario. Regarding SAs and core integrity, there are still several uncertainties, so it would be reasonable to link this strategy to hydrogen concentration and not to a specific timing. Consequently, the optimal window for the vent operation will be when the hydrogen concentration reaches a gas volume fraction of $4 \%$ with a slope of $2.5 \cdot 10^{-5} \mathrm{~s}^{-1}$. After that time, the hydrogen risk is reduced when venting is activated. It is mentionable that this hydrogen concentration is similar to those which are the set point to enter SAG 7. This optimal window finishes after the hydrogen generation peak ( $12500 \mathrm{~s})$ because the DDT regime, which appears on certain regions, cannot be avoided. In addition the earlier the hydrogen is evacuated from the containment the better relative to hydrogen risk.

If the spray system is available at that time, it is required to be activated before venting to wash out the FPs. If it is not available, then the vent system should be activated as early as possible when inside the optimal window to spread as minimum FPs as possible. 


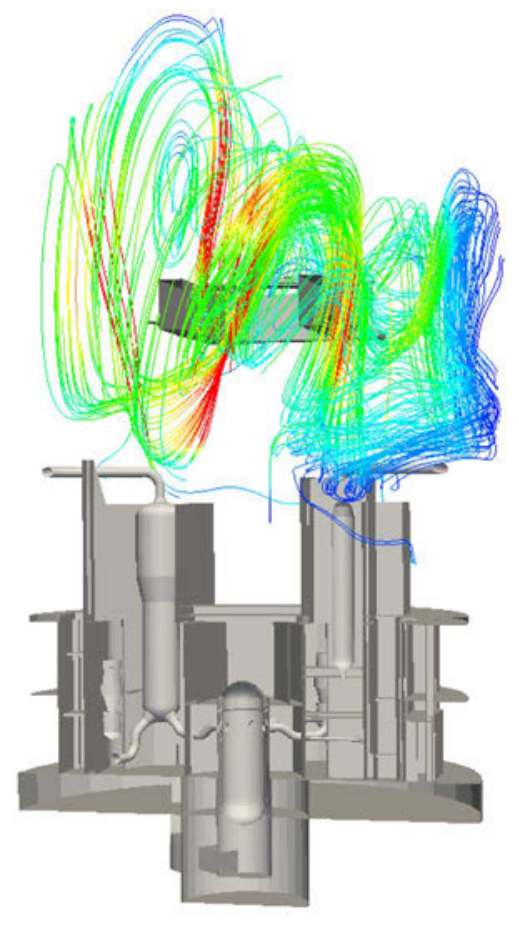

Time: 6500.0 seconds

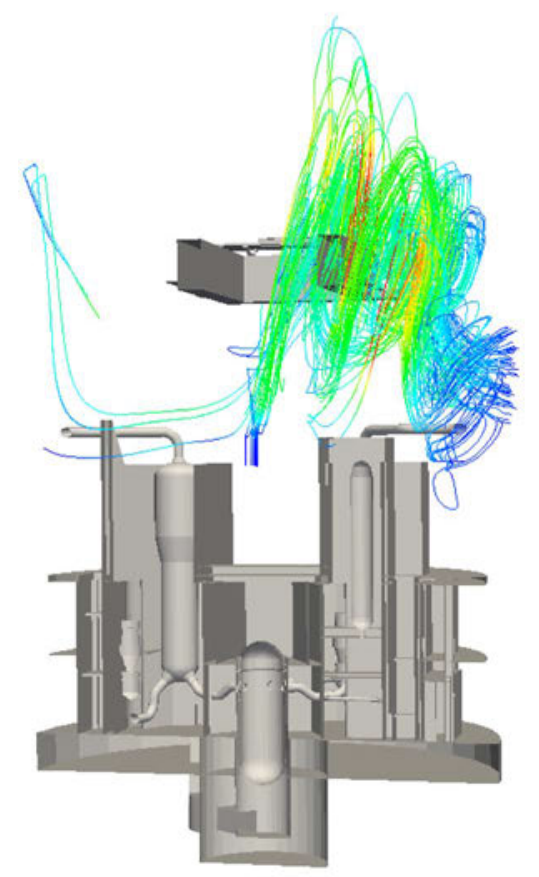

Time: 7000.0 seconds
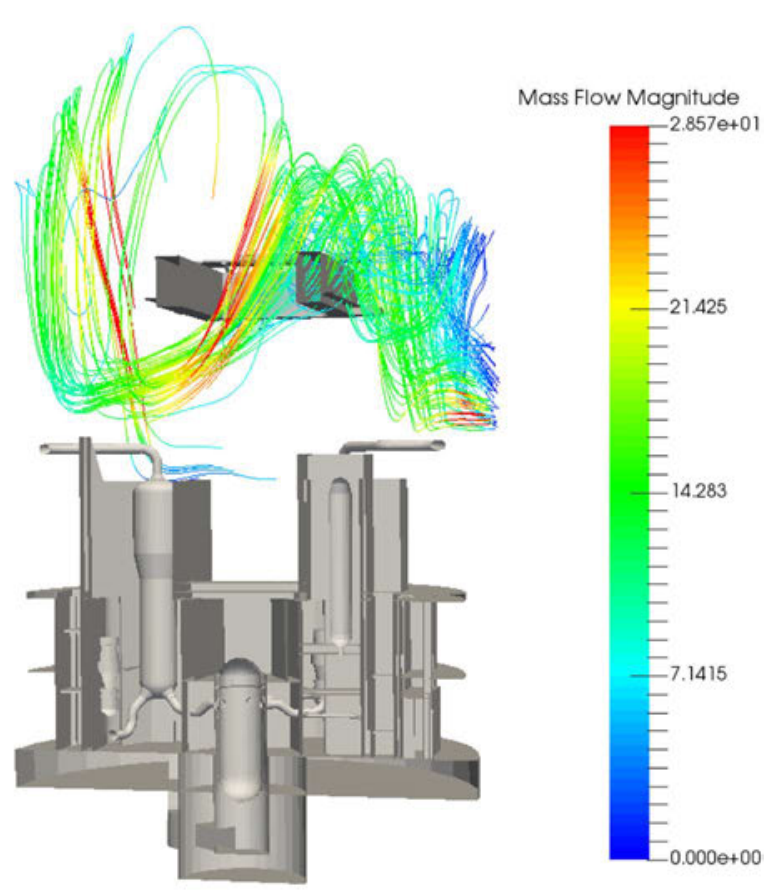

\section{Time: 6525.0 seconds}

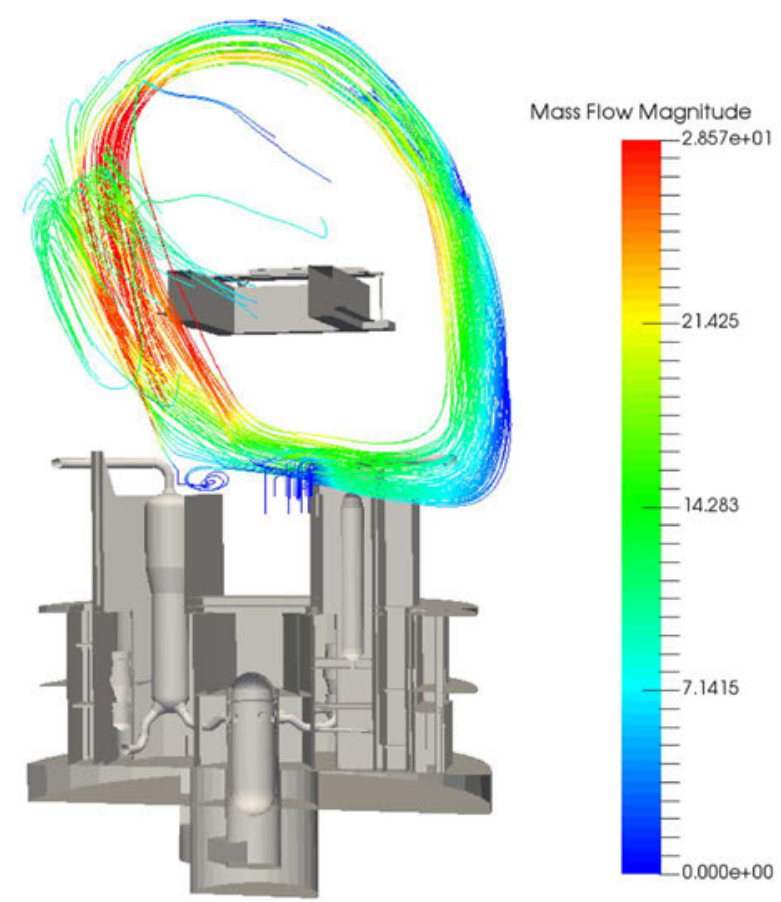

Time: 7550.0 seconds

Fig. 12. Mass flow patterns inside containment prior (up left), during (up right, down left) and after (down right) venting. (Sensitivity 4).

\section{Conclusions}

During a SA, hydrogen can be generated creating a threat on con tainment and equipment integrity. The SAMGs have been developed to guide the TSC in taking the best decisions during the accident man agement. However, the decision for venting the containment in order to reduce the hydrogen risk is a strategy that has not been studied in detail with the current computing capabilities. Moreover, the hydrogen risk has not been quantified until now. Consequently, in this study, the Tau parameter is created and defined in order to quantify the hydrogen risk, and then applied it to SA management strategies.

The Tau parameter takes into account three aspects of the hydrogen hazardousness: the time a hydrogen cloud spends within the flamm ability limits, the mass of hydrogen that is within the flammability limits, and the combustion regime achieved (SD, FA or DDT). With this parameter it is possible to reduce a simulation to a single value to 

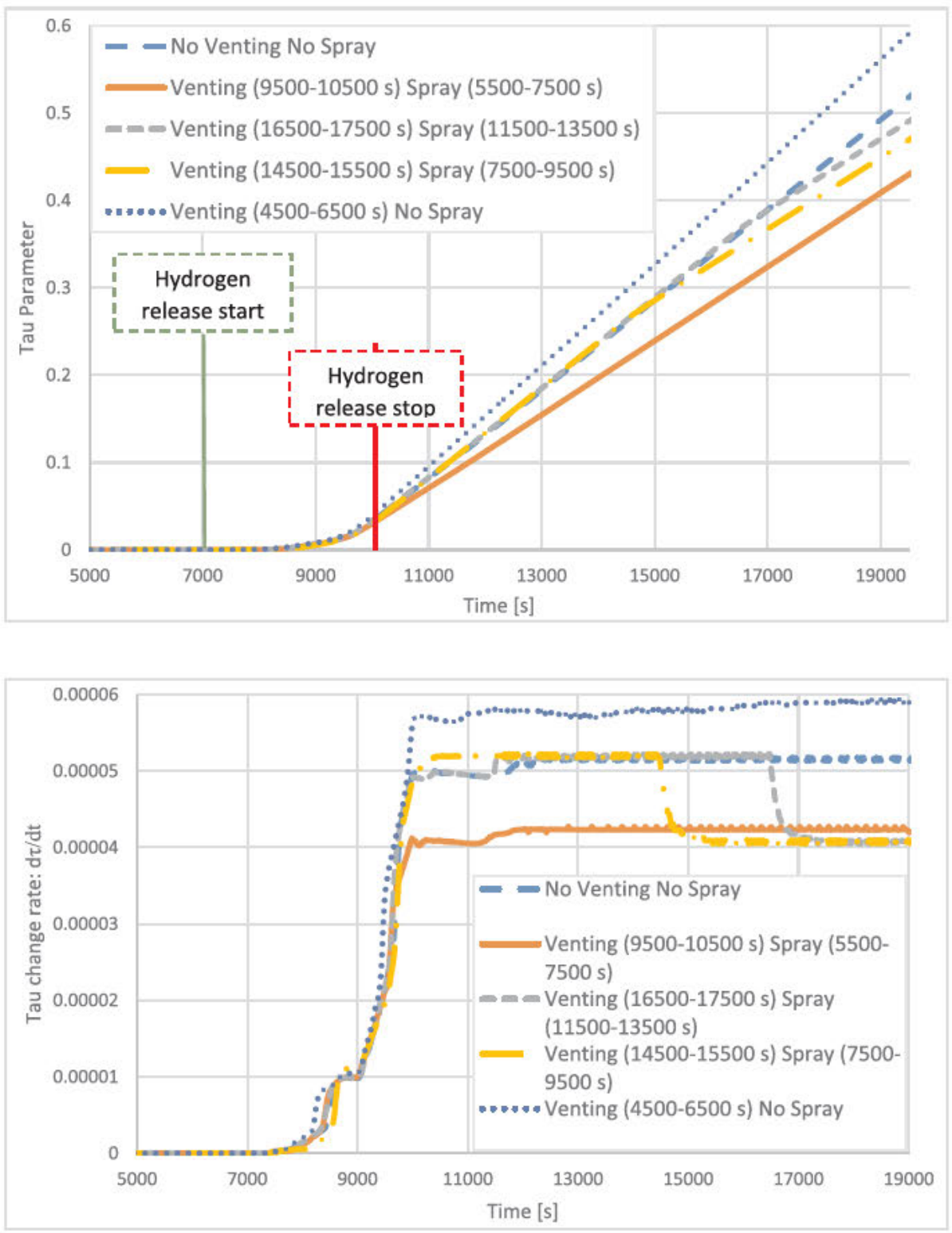

Fig. 13. Temporal evolution of Tau in representative cases.

Fig. 14. Tau temporal change rate in representative cases. quantify the hydrogen risk, and that makes possible the quantitative comparison of different scenarios.

As an application, a sensitivity analysis during a SBO with con tainment venting and spray system have been performed. The sensi tivity analysis includes different operation times for venting and spraying activation. The results of this analysis have shown the fol lowing:

1. Venting the containment before the hydrogen release in order to reduce the amount of oxygen is not effective because there is enough supply of oxygen remaining in the containment, and because it will vent steam, that helps in inerting the containment. All simulations with a venting prior to the hydrogen release show a higher Tau value (hydrogen risk) than the no venting simulation. Additionally, venting the containment before the hydrogen release creates flow patterns inside the containment that influence the Tau value, but not in an easily predictable manner.

2. The optimal time for venting is right after the hydrogen release peak occurs. This way, the most severe deflagration regime is normally avoided in most of the regions. Approximately 100 kilograms of hydrogen are evacuated from the containment in a $1000 \mathrm{~s}$ venting, reducing even more the Tau value because this hydrogen mass does not stay in the containment.

3. The spray timing has a marginal influence on Tau compared to venting. However, if the spray is activated during the hydrogen peak, the steam starts condensing, and that slightly increases the hydrogen concentration and therefore the potential to reach a DDT regime.

4. The venting strategy has therefore an optimal time window. This fact has encouraged the authors to present a proposal for optimal venting time to decrease the hydrogen risk. To vent in this specific window, an indicator of hydrogen concentration could be used to help the operators during a SA.

Summarizing all the results, it is now clear that the venting strategy, if properly performed, can reduce the hydrogen risk inside the con tainment. During a SBO scenario, the venting strategy, together with the PAR actuation, may be the only options to deal with hydrogen re leases, and this could avoid containment damage and emission of large quantities of FPs to the environment. This knowledge could help in the future development and/or revision of SAMGs for hydrogen manage ment guidelines. 


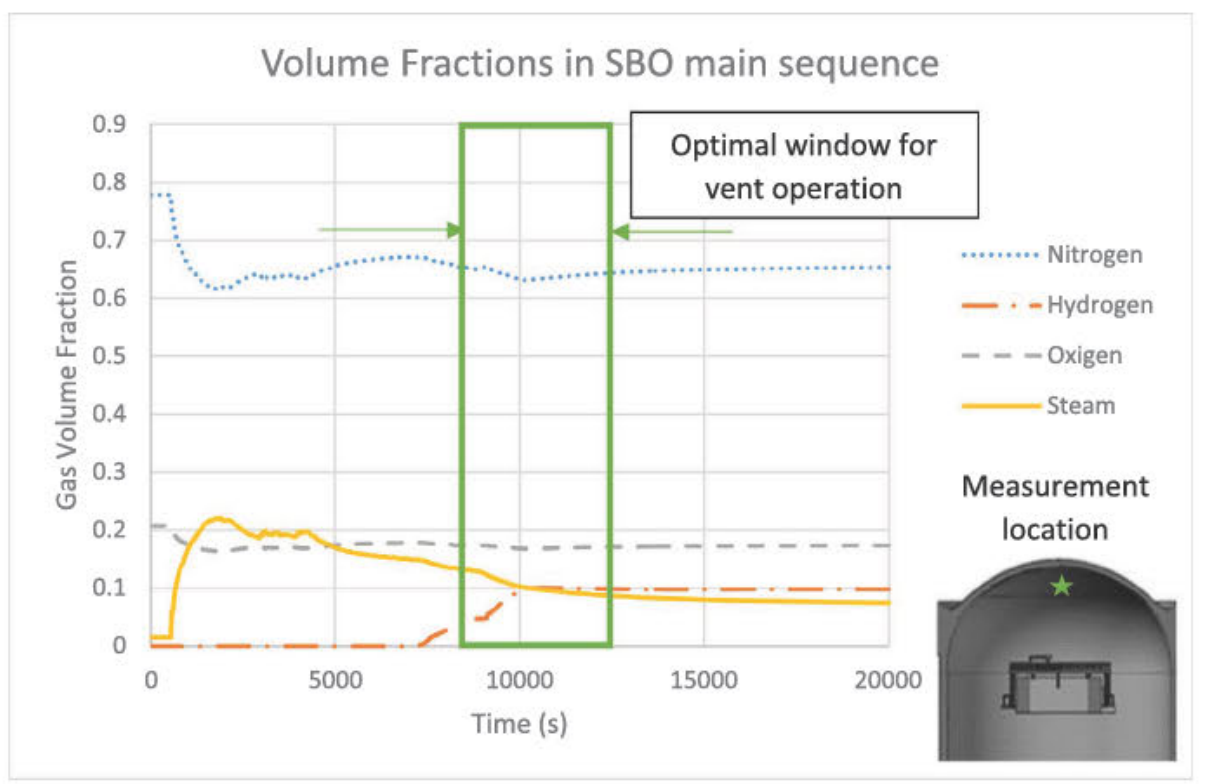

Fig. 15. Gas volume fractions in an indicator in the dome region.

\section{Acknowledgment}

This work has been funded by the Spanish Ministry of Competitiveness and Economy within PYGAS project: ENE2015 67638 R (MINECO/FEDER). Its support is gratefully acknowledged.

The author acknowledges the computer resources and technical assistance provided by the Centro de Supercomputación y Visualización de Madrid (CeSViMa).

The authors want to express their deep gratitude to EPRI and Zachry company personnel, especially Tom George, for their valuable technical support and help during the development of this work.

\section{References}

Andreani, M., Haller, K., Heitsch, M., Hemström, B., Karppinen, I., Macek, J., Schmid, J., Paillere, H., Toth, I., 2008. A benchmark exercise on the use of CFD codes for containment issues using best practice guidelines: a computational challenge. Nucl. Eng. Des. 238, 502-513. http://dx.doi.org/10.1016/j.nucengdes.2007.01.021.

Andreani, M., Kapulla, R., Zboray, R., 2012. Gas stratification break-up by a vertical jet: simulations using the GOTHIC code. Nucl. Eng. Des. 249, 71-81. http://dx.doi.org/ $10.1016 / \mathrm{j}$.nucengdes.2011.06.004.

Andreani, M., Paladino, D., George, T., 2010. Simulation of basic gas mixing tests with condensation in the PANDA facility using the GOTHIC code. Nucl. Eng. Des. 240, 1528-1547. http://dx.doi.org/10.1016/j.nucengdes.2010.02.021.

Andreani, M., Putz, F., Dury, T., Gjerloev, C., Smith, B., 2003. On the application of field codes to the analysis of gas mixing in large volumes: case studies using CFX and GOTHIC. Ann. Nucl. Energy 30, 685-714. http://dx.doi.org/10.1016/S03064549(02)00113-5.

Bachellerie, E., Arnould, F, Auglaire, M. de Boeck, B., Braillard, O, Eckardt, B., Ferroni, F., Moffett, R., 2003. Generic approach for designing and implementing a passive autocatalytic recombiner PAR-system in nuclear power plant containments. Nucl Eng. Des. 221, 151-165. http://dx.doi.org/10.1016/S0029-5493(02)00330-8.

Bauwens, C.R., Dorofeev, S.B., 2014. CFD modeling and consequence analysis of an accidental hydrogen release in a large scale facility. Int. J. Hydrogen Energy 20447-20454. http://dx.doi.org/10.1016/j.jihydene.2014.04.142.

Bielert, U., Breitung, W., Kotchourko, a., Royl, P., Scholtyssek, W., Veser, a., Beccantini, A., Dabbene, F., Paillere, H., Studer, E., Huld, T., Wilkening, H., Edlinger, B., Poruba, C., Mohaved, M., 2001. Multi-dimensional simulation of hydrogen distribution and turbulent combustion in severe accidents. Nucl. Eng. Des. 209, 165-172. http://dx. doi.org/10.1016/S0029-5493(01)00399-5.

Bocanegra, R., Jimenez, G., Fernández-Cosials, K., 2017. GOTHIC Advisory Group Meeting. In: GOTHIC Advisory Group Meeting Madrid. Madrid.

Bocanegra, R., Jimenez, G., Fernández-Cosials, M.K., 2016. Development of a PWR-W GOTHIC 3D model for containment accident analysis. Ann. Nucl. Energy 87, 547-560. http://dx.doi.org/10.1016/j.anucene.2015.10.022.

Boivin, P., Jiménez, C., Sánchez, A.L., Williams, F.A., 2011. A four-step reduced mechanism for syngas combustion. Combust. Flame 158,1059-1063. http://dx.doi.org/ $10.1016 /$ j.combustflame.2010.10.023.

Breitung, W., Royl, P., 2000. Procedure and tools for deterministic analysis and control of hydrogen behavior in severe accidents. Nucl. Eng. Des. 202, 249-268. http://dx.doi. org/10.1016/S0029-5493(00)00380-0.
Burelbach, J., Lee, S., Plys, M., De la Rosa, J.C., Foronós, J., 2015. Analysis of Potential Risk Caused by Hydrogen and Carbon Monoxide in Buildings attached to Containment for Ascó 1 \& 2 and Vandellós II NPPs. In: PSA 2015. Sun Valley, Idaho, pp. 583-589.

Byun, C.S., Jerng, D.W., Todreas, N.E., Driscoll, M.J., 2000. Conceptual design and analysis of a semi-passive containment cooling system for a large concrete containment. Nucl. Eng. Des. 199, 227-242. http://dx.doi.org/10.1016/S0029-5493(00) 00228-4.

Camp, A.L., Cummings, J.C., Sherman, M.P., Kupiec, C.F., Healy, R.J., Caplan, J.S., Sandhop, J.R., Saunders, J.H., 1983. Light Water Reactor Hydrogen Manual/NUREG/ CR-2726.

Commission of the European Communities, 1991. Hydrogen Behaviour and Mitigation in Water-cooled Nuclear Power Plant. Commission of the European Communities.

del Corno, A., Morandi, S., Parozzi, F., Araneo, L., Casella, F., 2017. Experiments on aerosol removal by high-pressure water spray. Nucl. Eng. Des. 311, 28-34. http://dx. doi.org/10.1016/j.nucengdes.2016.06.043.

Dorofeev, S., 1996. Deflagration to detonation transition in large confined volume of lean hydrogen-air mixtures. Combust. Flame 104, 95-110. http://dx.doi.org/10.1016/ 0010-2180(95)00113-1.

Dorofeev, S.B., 2007. Evaluation of safety distances related to unconfined hydrogen explosions. Int. J. Hydrogen Energy 32, 2118-2124. http://dx.doi.org/10.1016/j. ijhydene. 2007.04.003.

Dorofeev, S.B., Kuznetsov, M.S., Alekseev, V.I., Efimenko, A.A., Breitung, W., 2001. Evaluation of limits for effective flame acceleration in hydrogen mixtures. J. Loss Prev. Process Ind. 14, 583-589. http://dx. doi.org/10.1016/S0950-4230(01)00050-X.

EPRI, 2014. GOTHIC Thermal Hydraulic Analysis Package, Version 8.1 (QA). Palo Alto, CA.

EPRI, 2012. Severe Accident Management Guidance Technical Basis Report (Vol I and II), ID 1025295.

EPRI, 1992. Severe Accident Management Guidance Technical Basis Report (Volume 2: The Physics of Accident Progression). TR-101869-v2.

Fernández-Cosials, M.K., Jimenez, G., Lopez-Alonso, E., 2016. Analysis of a gas stratification break-up by a vertical jet using the GOTHIC code. Nucl. Eng. Des. 297, 123-135. http://dx.doi.org/10.1016/j.nucengdes.2015.11.035.

Gómez-Torres, A.M., Sáinz-Mejía, E., Xolocostli-Munguía, J.V., López-Morones, R., FilioLópez, C., Royl, P., 2015. CFD analysis of hydrogen volumetric concentrations in a Hard Venting Containment System of a Mark II BWR. Ann. Nucl. Energy 85, 552-565. http://dx.doi.org/10.1016/j.anucene.2015.06.008.

Grgić, D., Zdenko, S., Bruno, G., 2012. Prediction of local hydrogen concentrations in PWR containment using GOTHIC code. Trans. Am. Nucl. Soc. 24-28.

HSE, 2011. Generic Design Assessment - New Civil Reactor Build Step 4 Fault Studies Containment and Severe Accident Assessment of the EDF and AREVA UK EPRTM Reactor.

Huang, X.G., Yang, Y.H., Cheng, X., Al-Hawshabi, N.H.A., Casey, S.P., 2011. Effect of spray on performance of the hydrogen mitigation system during LB-LOCA for CPR1000 NPP. Ann. Nucl. Energy 38, 1743-1750. http://dx.doi.org/10.1016/j. anucene. 2011.04.003.

Hultgren, A., Gallego-marcos, I., Villanueva, W., Kudinov, P., 2014. Large scale erosion of a helium stratified layer by a vertical jet using the GOTHIC code. In: The 10th International Topical Meeting on Nuclear Thermal-Hydraulics, Operation and Safety (NUTHOS-10). pp. 1-18.

IAEA, 2009. Severe Accident Management Programmes for Nuclear Power Plants. Safety Guide No. NS-G-2.15. Safety Guide No. NS-G-2.15 83 .

IEEE, 1974. IEEE Standard for Qualifying Class 1E Equipment for Nuclear Power Generating Stations. IEEE std 323-1974. doi: 10.1109/IEEESTD.1974.6568022. Jimenez, G., Fernández-Cosials, M.K., Bocanegra, R., Queral, C., 2017. Analysis of the 
equipment and instrumentation qualification criteria using 3D containment models. Nucl. Eng. Des. 323, 28-38. http://dx.doi.org/10.1016/j.nucengdes.2017.07.038.

Jong Tae, J.R.K., Seong Wan, H., Sang Baik, K., Hee Dong, K., Un Jang, L., Travis, P.R., 2004. 3-Dimensional analysis of the steam-hydrogen behavior from a small break loss of coolant accident in the APR1400 containment. J. Korean Nucl. Soc.

Karwat, H., Bardelay, J., Hashimoto, T., Koroll, G., Krause, M., L’Heriteau, J.P., Lundström, P., Notafrancesco, A., Royl, P., Schwinges, B., Tezuka, H., Tills, J., Royen, J., 1999. State-of-the-art report on containment thermalhydraulics and hydrogen distribution, NEA/CSNI/R(99)16, Prepared by an OECD/NEA Group of Experts.

Kim, J., Hong, S.-W., 2015. Analysis of hydrogen flame acceleration in APR1400 containment by coupling hydrogen distribution and combustion analysis codes. Prog. Nucl. Energy 78, 101-109. http://dx.doi.org/10.1016/j.pnucene.2014.09.003.

Kljenak, I., Bentaib, A., Jordan, T., 2012. Early containment failure. In: Seghal, Bal Raj (Ed.), Nuclear Safety in Light Water Reactors. Elsevier, pp. 185-306. http://dx.doi. org/10.1016/B978-0-12-388446-6.00003-4.

Knudson, D.L., Rempe, J.L., Lutz, R.J., 2015. Scoping Study Investigating PWR Instrumentation during a Severe Accident Scenario.

Kuan, P., Hanson, D.J., Pafford, D.J., Quick, K.S., Witt, R.J., 1994. Implications for Accident Management of Adding Water to a Degrading Reactor Core, NUREG/CR6158.

Kudriakov, S., Dabbene, F., Studer, E., Beccantini, a., Magnaud, J.P., Paillère, H., Bentaib, a., Bleyer, a., Malet, J., Porcheron, E., Caroli, C., 2008. The TONUS CFD code for hydrogen risk analysis: physical models, numerical schemes and validation matrix. Nucl. Eng. Des. 238, 551-565. http://dx.doi.org/10.1016/j.nucengdes.2007.02.048.

Li, Y.B., Cao, X.W., 2015. Strategy evaluation for fire spray system on Advanced Passive PWR Severe Accident Management Guideline. Prog. Nucl. Energy 85, 319-324. http://dx.doi.org/10.1016/j.pnucene.2015.07.001.

López-Alonso, E., 2016. A proposed methodology for passive autocatalytic recombiner sizing and location in LWR containments. PhD Thesis Universidad Politécnica de Madrid.

Malet, J., Huang, X., 2015. Influence of spray characteristics on local light gas mixing in nuclear containment reactor applications. Comput. Fluids 107, 11-24. http://dx.doi. org/10.1016/j.compfluid.2014.10.002.

Martín-Valdepeñas, J.M., Jiménez, M.A., Martin-Fuertes, F., Fernández, J.A., 2000 Definición de los parámetros fundamentales de los escenarios accidentales de riesgo de hidrógeno para centrales prototípicas españolas W-PWR de segunda y tercera generación. Informe de la cátedra de tecnología Nuclear, Madrid.

Martín-Valdepeñas, J.M., Jiménez, M.A., Martín-Fuertes, F., Fernández, J.A., 2007. Corrigendum to "Improvements in a CFD code for analysis of hydrogen behaviour within containments" [Nucl. Eng. Design 237 (2007) 627-647]. Nucl. Eng. Des. 311, 224. http://dx.doi.org/10.1016/j.nucengdes.2016.12.019.

Martín-Valdepeñas, J.M., Jiménez, M.a., Martín-Fuertes, F., Fernández, J.a., 2007. Improvements in a CFD code for analysis of hydrogen behaviour within containments. Nucl. Eng. Des. 237, 627-647. http://dx.doi.org/10.1016/j.nucengdes.2006 09.002 .

Mathworks, 2015. MATLAB and Statistics Toolbox Release 2015a.

McAdams, W.H., 1954. Natural Convection, in: W-Hill, M. (Ed.), Heat Transmission. United States of America, pp. 165-183.

NEI, 2012. Diverse and Flexible Coping Strategies (FLEX) Implementation Guide. NEI 12-06.

NEI, 1994. Severe Accident Issue Closure Guidelines. NUMARC91-04.

OECD/NEA, 2014a. NEA/CSNI/R(2014) 8. Status Report on Hydrogen Management and Related Computer Codes.

OECD/NEA, 2014b. Assessment of CFD Codes for Nuclear Reactor Safety Problems. Nea/
Csni/R(2014) 12 .

OECD/NEA, 2014c. Status Report on Filtered Containment Venting. NEA/CSNI/R (2014) 7.

OECD/NEA, 2013. The Fukushima Daiichi Nuclear Power Plant Accident: OECD/NEA Nuclear Safety Response and Lessons Learnt.

OECD/NEA, 2010. OECD/NEA THAI Project Hydrogen and Fission Product Issues Relevant for Containment Safety Assessment under Severe Accident Conditions Final Report 1-33. doi: NEA/CSNI/R(2010) 3.

OECD/NEA, 2000. Flame Acceleration and Deflagration-to-Detonation Transition in Nuclear Safety. NEA/CSNI/R(2000) 7.

Ofstun, R., Scobel, J., 2006. Westinghouse Containment Analysis Methodology. WCAP16608-NP 1-164.

Paladino, D., Zboray, R., Andreani, M., Dreier, J., 2010. Flow transport and mixing in duced by horizontal jets impinging on a vertical wall of the multi-compartment PANDA facility. Nucl. Eng. Des. 240, 2054-2065. http://dx.doi.org/10.1016/j. nucengdes.2010.03.036.

Papini, D., Andreani, M., Ničeno, B., Prasser, H., Scherrer, P., Psi, I., Ag, K.G., 2015 Simulation of hydrogen distribution in the containment during a severe accident with fast hydrogen-steam release. In: NURETH-16. Chicago, pp. 1474-1487.

Philipov, S., Filipov, K., 2014. Hydrogen Distribution Assessment With Cfd Tool in Help of Severe Accident Management Needs and Specifics in Hydrogen Safety, in: Icone2230412. Prague, pp. 1-5. doi: 10.1115/ICONE22-30412.

Prabhudharwadkar, D.M., Iyer, K.N., Mohan, N., Bajaj, S.S., Markandeya, S.G., 2011. Simulation of hydrogen distribution in an Indian Nuclear Reactor Containment. Nucl. Eng. Des. 241, 832-842. http://dx.doi.org/10.1016/j.nucengdes.2010.11.012.

Reinecke, E.-A., Bentaib, A., Kelm, S., Jahn, W., Meynet, N., Caroli, C., 2010. Open issues in the applicability of recombiner experiments and modelling to reactor simulations. Prog. Nucl. Energy 52, 136-147. http://dx.doi.org/10.1016/j.pnucene.2009.09.010.

Royl, P., Rochholz, H., Breitung, W., Travis, J., Necker, G., 2000. Analysis of steam and hydrogen distributions with PAR mitigation in NPP containments. Nucl. Eng. Des. 202, 231-248. http://dx.doi.org/10.1016/S0029-5493(00)00332-0.

Sánchez, A.L., Williams, F.A., 2014. Recent advances in understanding of flammability characteristics of hydrogen. Prog. Energy Combust. Sci. 41, 1-55. http://dx.doi.org/ 10.1016/j.pecs.2013.10.002.

Serrano, C., Jimenez, G., del Molina, M.C., López-Alonso, E., Justo, D., Zuriaga, J.V., González, M., 2016. Proposed methodology for Passive Autocatalytic Recombiner sizing and location for a BWR Mark-III reactor containment building. Ann. Nucl. Energy 94, 589-602. http://dx.doi.org/10.1016/j.anucene.2016.03.022.

Stamps, D., Berman, M., 1991. High-temperature hydrogen combustion in reactor safety applications. Nucl. Sci. Eng. 109, 39-48.

Vayssier, G., Sehgal, B.R., Dinh, N., Journeau, C., Fischer, M., 2012. Severe Accident Management, in: Nuclear Safety in Light Water Reactors. Elsevier, pp. 519-588. doi: 10.1016/B978-0-12-388446-6.00006-X.

Williams, F.A., 1985. The Mathematics of Combustion. Society for Industrial and Applied Mathematics. doi: 10.1137/1.9781611971064

Xiao, J., Breitung, W., Kuznetsov, M., Zhang, H., Travis, J.R., Redlinger, R., Jordan, T., 2017. GASFLOW-MPI: a new 3-D parallel all-speed CFD code for turbulent dispersion and combustion simulations Part II: First analysis of the hydrogen explosion in Fukushima Daiichi Unit 1. Int. J. Hydrogen Energy. http://dx.doi.org/10.1016/j. ijhydene.2017.01.219.

Xiao, J., Travis, J.R., 2013. How critical is turbulence modeling in gas distribution simulations of large-scale complex nuclear reactor containment? Ann. Nucl. Energy 56, 227-242. http://dx.doi.org/10.1016/j.anucene.2013.01.016. 